\title{
The post impact response of flax/UP composite laminates under low velocity impact loading
}

H. N. Dhakal ${ }^{* a}$, H. Ghasemnejad ${ }^{\text {b }}$, Z. Y. Zhang ${ }^{\text {a }}$, S. O. Ismail ${ }^{\text {a }}$, V. Arumugam ${ }^{\mathrm{c}}$

${ }^{a}$ Advanced Polymer and Composites (APC) Research Group,

School of Engineering, University of Portsmouth, Anglesea Road, Anglesea Building, Portsmouth, Hampshire, PO1 3DJ, U.K.

${ }^{\mathrm{b}}$ School of Aerospace, Transport and Manufacturing, Cranfield University, Cranfield, Bedfordshire MK43 0AL, U.K.

${ }^{c}$ Department of Aerospace Engineering, MIT campus, Chromepet, Anna University, Chennai-44,TamilNadu, India.

\begin{abstract}
Flax fiber reinforced unsaturated polyester (UP) composite laminates were fabricated by vacuum bagging process and their impact and post-impact responses were investigated through experimental testing and finite element simulations. Samples of $60 \mathrm{~mm}$ x $60 \mathrm{~mm}$ x $6.2 \mathrm{~mm}$ were cut from the composite laminates and were subjected to a low-velocity impact loading to near perforation using hemispherical steel impactor at three different energy levels, 25, 27 and 29 Joules, respectively. Post impact was employed to obtain full penetration. The impacted composite plates were modelled with various lay-ups using finite element software LS-DYNA (LS-DYNA User's Manual 1997) to provide a validated FE model for the future investigation in the field. The effects of impact and post impact on the failure mechanisms were evaluated using scanning electron microscopy (SEM). Parameters measured were load bearing capability, energy absorption and damage modes. The results indicate that both peak load and the energy absorption were reduced significantly after the post impact events. Consequently, it was observed from the visual images of the damages sites that the extent of damage increased with increased incident energy and post impact events.
\end{abstract}

Keywords: Polymer-matrix composites (PMCs); Composite laminates; Low-velocity impact; Finite elements analysis (FEA); LS-DYNA.

* Corresponding author. Tel: + 44 (0) 239284 2582; fax: + 44 (0) 2392842351.

\section{E-mail: hom.dhakal@port.ac.uk (H. N. Dhakal)}




\section{Nomenclature}

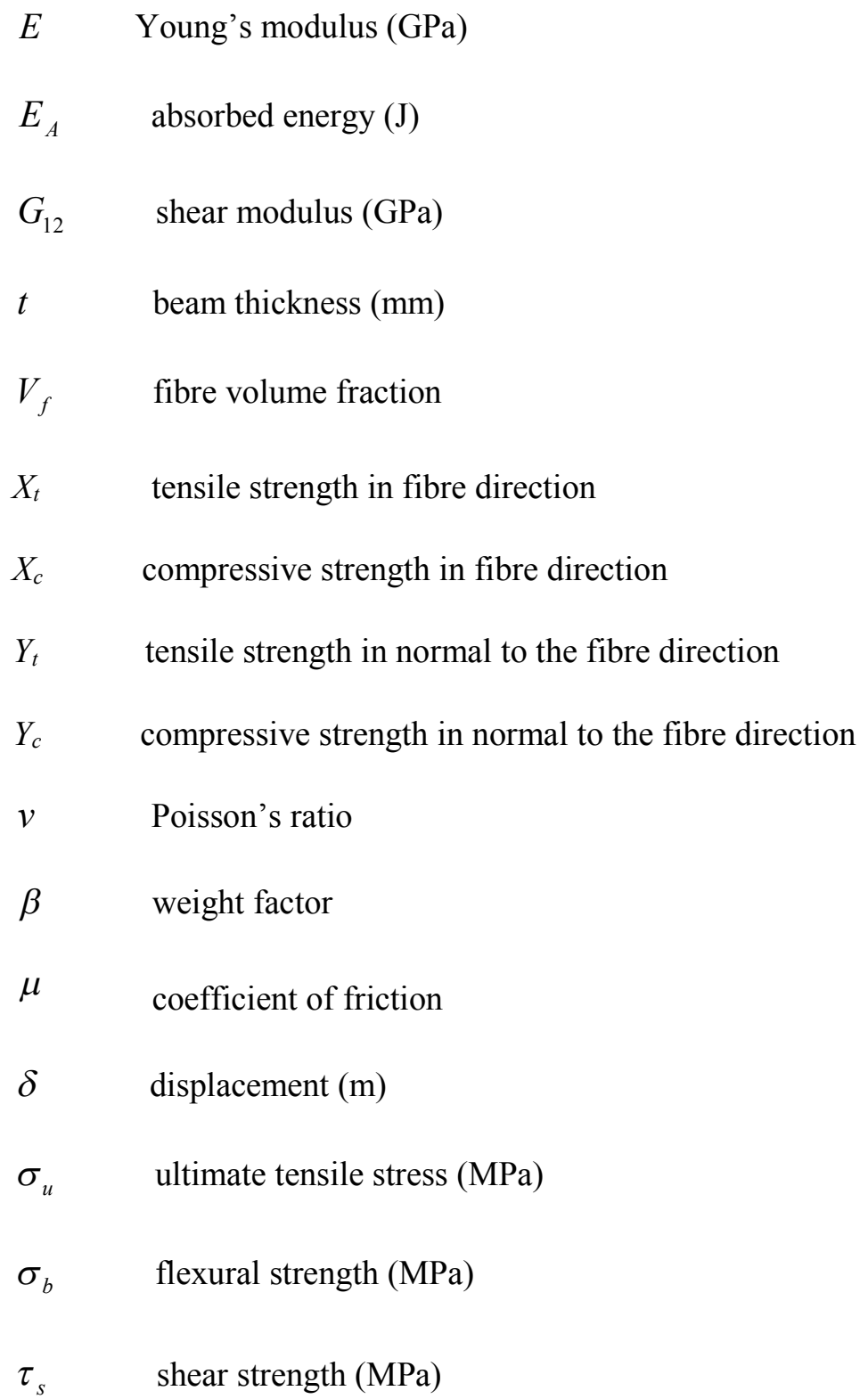




\section{INTRODUCTION}

Advanced fibre-reinforced polymer (FRP) composites have gained significant popularity in structural applications due to their high strength to weight ratio and superior mechanical properties. However, concerns over global warming and the end-of-life of nonbiodegradable carbon and glass fibre reinforcements in composite materials, consumer's pressure, new government's legislation and need for light weight structural materials have motivated research into materials which are also biodegradable, renewable and environmentally sustainable [1-3]. As the cost of non-renewable sources of material becomes more expensive, natural fibres can be a viable alternative as reinforcements for composite materials $[4,5]$. The use of natural fibres reinforcemed polymeric composite materials have been successfully used in a wide range of applications in recent years due to their aboundant availability, lower density, and much higher specific strength than conventional fibre reinforced composites [6-8]. The need for light weight and less $\mathrm{CO}_{2}$ emmissing structures have large growth potential in demand for natural fibre reinforcements. Therefore, in recent years, automotive industry is leading the way in utilising natural fibre reinforced composite materials in various non-structural parts such as door trim panels, parcel shelves and other interior parts. However, there are still significant barriers for structural and semi-structural applications of these composite materials due to their vulnerability to low velocy impact damage, lower stiffness among other mechanical properties [9, 10]. Also, their property variability, inherent moisture absorbing characteristics can lead to poor fibre matrix interaction causing reduced composite properties and thus, affecting the long-term performance [11]. For these composites to be used in structural components, it is important that the designers and manufacturers understand how these materials behave under different loading conditions including fracture toughness, fatigue and their impact loading. 
Low velocity impact damage can take place in composites when the objects such as runway debris and hand tools fall down on composites during their service life, which cause different failure modes such as matrix cracking, delamination at the interface, fibre breakage and fibre pull-out [12]. Therefore, understanding and the characterization of the effects of various failure modes due to the low velocity impact is necessary in a natural fiber reinforced composites in order to ascertain the capability of the composites to withstand impact load during their service life [13, 14].

Several studies have been carried out to understand the low velocity impact response of carbon and glass fiber reinforced composite materials and structures. An in-depth review undertaken by Cantwell and Morton [15] has helped researchers to understand the important phenomenon contributing the impact-induced failure of composite laminates. Choi et al. [16] investigated the impact induced delamination of composites using both experimental and numerical analyses of the damage process. Their work suggested that the understanding of failure of composites due to low velocity impact is always difficult due to several factors involved. Wisheart and Richardson [17] analysed the impact response of complex geometry pultruded glass/polyester composites. Their report suggests that the residual strengths in tension, compression, bending and fatigue life of composite were reduced to varying degrees depending on the dominant failure mode. Mitrevski et al. [18] studied the influence of impactor shape on the impact damage of composite laminates. Their results demonstrated that the impactor shape plays a big role on the damage response of composite materials.

Similarly, low velocity impact damage response of natural fibre reinforced composite materials has been subject of many experimental investigations. Bledzki et al. [19] studied the falling weight impact damage of Abaca fibre reinforced polypropylene composite and compared with jute and flax fibre PP composites. Benevolenski et al. [20] investigated the transverse perforation impact behavior of flax mat reinforced PP composites with addition 
discontinuous cellulose and discontinuous glass fibre mat. Santulli and his co-workers [21, 22] studied the falling weight impact damage characterisation on flax/epoxy laminates as well as other bast fibre reinforced polymeric composites. Their study reported difficulty of predicting impact damage characteristics of natural fibre composites. Ghasemnejad et al. [23, 24] studied the effect of stitching on the impact damage behavior of single and multidelaminated flax hybrid composite beams. They reported that stitching can significantly improve the energy absorption capabilities of composite structures. It is evident from these literatures that the impact damage characteristics of natural fibre composites with polymeric matrices like PP, epoxy, and unsaturated polyester, have been well studied. However, not much has been reported on the relationship between the impact and post impact response of the natural fibre composites especially flax/UP laminates in comparison with experimental and numerical results.

In this study, the effect of flax fibre reinforcement on the low velocity impact and post- impact response of flax/UP composites are investigated. For this, the flax/UP composites were impacted at impact energies ranging from 25 Joules to 29 Joules sufficient to create impact damage near perforation, but not full penetration. The post impact energy of 25 Joules was employed to all impacted specimens to obtain full penetration and the effect of impact and post impact performance was evaluated in terms of load bearing capability, energy absorption capability and damage modes of the specimens with regards to increasing incident energy using both experimental and numerical finite element analysis (FEA) model.

\section{MATERIALS AND METHODS}

\subsection{Materials}

Low viscosity unsaturated polyester (UP) with the commercial name of Enydyne I 68835 supplied by Cray Valley was used as matrix in the preparation of the composite laminates. The matrix material was mixed with curing catalyst, methyl ethyl ketone peroxide 
(MEKP) at a concentration of $1.5 \mathrm{wt} . \%$. The flax fibre as reinforcement used was FLAXPLY supplied by Lineo Company as a balanced fabric $0 / 90$ of $200 \mathrm{~g} / \mathrm{cm}^{2}$ in weight. Physical and mechanical properties of flax fibre are presented in Table 1.

\subsection{Composite preparations}

The composite laminates were fabricated by hand lay-up and vacuum bagging process in plate of $6.2 \mathrm{~mm}$ thickness. The fibre weight percentage was $33 \%$ and the void content was 5\%. The void content was calculated according to ASTM D2734-94 and the percentage of weight was calculated by means of weighing the fibre content.

\subsection{Drop weight impact test}

The low-velocity impact tests were performed using an instrumented Zwick/Roell HIT230F drop weight test machine with an impactor of constant mass $23.11 \mathrm{~kg}$ from an initial height of $110 \mathrm{~mm}$ with a hemispherical steel tup diameter of $19.8 \mathrm{~mm}$, as depicted in Figure 1. The drop height of the impactor was adjusted to generate 25, 27 and 29 Joules of incident impact energy. The tests were performed on a square specimens of side length $60 \mathrm{~mm}$ with $6.2 \mathrm{~mm}$ thickness at room temperature. A catcher mechanism was activated to avoid the multiple damage on the specimens. The incident energies were obtained from adjusting the drop height of the impactor and calculated using typical energy equation:

$$
E_{i}=m g h
$$

where, $E_{i}$ is incident impact energy, $m$ is mass of the impactor, $g$ is gravity and $h$ is height. The post impact energy of 25 Joules was employed to all impacted specimens in order to assess the effect of post impact performance of the composites studied.

\subsection{Finite element analysis}

\subsubsection{Finite element modelling (FEM)}


Due to costly and time consuming process of experimental studies, numerical modelling has been performed to introduce a new method on damage analysis of composite structure. In order to create a FE model to predict the post impact response of composite structures, the composite plates were modelled with lay-ups according to the experimental studies using finite element software LSDYNA (LSDYNA User's Manual 1997). The size of the composite beam was $60 \times 60 \mathrm{~mm}^{2}$ with a thickness of $6.2 \mathrm{~mm}$. All results have been validated against the experiments to prove the accuracy of this method.

The composite plates were modelled with lay-ups according to the experimental studies using finite element software LS-DYNA (LS-DYNA User's Manual 1997). The size of the composite beam was $60 \times 60 \mathrm{~mm}^{2}$ with a thickness of $6.2 \mathrm{~mm}$.

The composite plate was modelled based on Belytschko-Lin-Tsay quadrilateral shell elements. This shell element is based on a combined co-rotational and velocity strain. All surfaces of the model were meshed using quadratic shell element and the size of an element was $1 \times 1 \mathrm{~mm}^{2}$ in the middle of plate as shown in Figure 2 . The striker was modelled as a rigid block using solid element. Mesh sensitivity analysis has been performed in previous work of authors and this mesh size is referred to this work [23].

The delamination failure mode needs three-dimensional representation of the constitutive equation and kinematics, and cannot be treated in thin shell theory. This failure mode requires micro-mechanical modelling of the interface between layers and cannot be treated in thin shell theory that deals with stresses at macro levels. Thus, debonding and delamination are usually ignored when thin shell element are used to model failure in composite modelling. In this work, post-impact of damaged specimen was modelled using integration point (IP) through the thickness of the element and each integration point is used to represent each composite layer. In this case, the thickness of integration point layers at 
those places which are allocated for delamination was reduced to zero. This situation introduces the damaged area between the related layers.

Material model 54 of LS-DYNA was selected to model the damage of flax composite plate. The Chang-Chang [25] failure criterion which is the modification of the Hashin's [26] failure criterion was chosen for assessing lamina failure. The post-failure conditions in the Material 54 model are somewhat different from the original Chang-Chang equations. In this model, four failure modes are categorised. These failure indicators are appointed on total failure for the laminas, where both the strength and the stiffness are set equal to zero after failure is encountered. In this model, as described below all material properties of lamina are checked using the following laws to determine the failure characteristic.

\subsubsection{Tensile fibre failure mode (fibre rupture)}

$$
\begin{aligned}
& \text { If } \sigma_{1}>0 \\
& \text { then } e_{f}{ }^{2}=\left(\frac{\sigma_{1}}{X_{t}}\right)^{2}+\beta\left(\frac{\sigma_{12}}{\tau_{S}}\right)^{2}-1 \\
& e_{f}{ }^{2}<0 \text { elastic }
\end{aligned}
$$

Where $\beta$ is a weighting factor for shear term in tensile fibre mode and its range is $0-1$ and $\sigma_{1}$ is stress in the fibre direction, $\sigma_{12}$ is transverse shearing stress, $X_{t}$ is tensile strength in fibre direction and $\tau_{s}$ is shear strength. When lamina failure occurs, all material constants are set to zero.

\subsubsection{Compressive fibre failure mode (fibre buckling)}

If $\sigma_{1}<0$

$$
\left\{\begin{array}{l}
e_{C}{ }^{2} \geq 0 \text { failed } \\
e_{C}{ }^{2}<0 \text { elastic }
\end{array}\right.
$$




$$
\text { then } e_{C}{ }^{2}=\left(\frac{\sigma_{1}}{X_{c}}\right)^{2}-1
$$

Where, $X_{c}$ is compressive strength in fibre direction.

After lamina failure by fibre buckling $E_{1}, v_{12}$ and $v_{21}$ are set to zero.

\subsubsection{Tensile matrix failure (matrix cracking under transverse tension and in-plane shear)}

$$
\begin{aligned}
& \text { If } \sigma_{2}>0 \\
& \text { then } e_{m}{ }^{2}=\left(\frac{\sigma_{2}}{Y_{t}}\right)^{2}+\left(\frac{\sigma_{12}}{\tau_{S}}\right)^{2}-1 \\
& e_{m}{ }^{2}<0 \text { elastic }
\end{aligned}
$$

Where $\sigma_{2}$ is stress in normal to the fibre direction, $Y_{t}$ is tensile strength in normal to the fibre direction and $Y_{c}$ is compressive strength in normal to the fibre direction. After lamina failure by matrix cracking, $E_{2}, v_{21}$ and $G_{12}$ are set to zero.

\subsubsection{Compressive matrix failure mode (matrix cracking under transverse compression and} in-plane shear)

$$
\begin{aligned}
& \text { If } \sigma_{2}<0 \\
& \text { then } e_{d}{ }^{2}=\left(\frac{\sigma_{2}}{2 \tau_{S}}\right)^{2}+\left[\left(\frac{Y_{c}}{2 \tau_{S}}\right)^{2}-1\right] \frac{\sigma_{2}}{Y_{c}}+\left(\frac{\sigma_{12}}{\tau_{S}}\right)^{2}-1
\end{aligned}
$$

In this work, the weight factor $\beta$ which is defined as the radio between shear stress and shear strength is set to 1 . The contact between the rigid plate and the specimens was modelled using a nodes impacting surface with a friction coefficient of 0.30 [25-26]. To 
prevent the penetration of the boundary by its own nodes, a single surface contact algorithm without friction was used. To simulate the impact condition, the loading velocity was applied to the rigid striker.

\subsection{Scanning electron microscopy (SEM)}

The fractured surfaces of the impacted composite specimens were examined using a SEM JSM 6100 at room temperature. After adhering to SEM stubs, a thin layer of gold/palladium was applied to the specimens prior to SEM examination.

\section{RESULTS AND DISCUSSION}

\subsection{Peak load and energy absorption}

The comparison of peak load and energy absorption of different specimens subjected to impact loadings are presented in Table 2 . The representative load against time curves recorded for samples just impacted at different energy levels are shown in Figure 3. It is evident from the results that there is not much difference between incipient damage load (a point where damage initiates) and the peak load for all specimens. It is quite clear that these two loads rather coincide to each other. The peak force taken by the composite laminates at 25, 27 and 29 Joules is very similar (Figure 3a). The load-time curves for all composite laminates are linear up to damage initiation point then reached to the peak load. Following damage initiation, the load dropped suddenly indicating decrease in the materials stiffness as a result of internal delamination or fibre matrix failures in the composites. The peak load represents the maximum load that composite specimens can withstand before undergoing major failure. The peak load taken by the post impacted samples for all three energy levels, 25, 27 and 29 Joules shows a considerable reduction (Figure 3b). This drastic reduction in peak load for post impacted specimens is attributed to the failure of the composite as a result of loss of stiffness due to the effect of post impact events. 
Energy absorption is an important factor that is commonly used to assess the ability of composite to withstand impact force. The influence of post impact response on the energy absorption for various incident energy levels is shown in Figures 4 (a-b). The corresponding energy plots from the experimental results obtained show a strong influence on post impact resistance as indicated by the amount of energy absorbed by the post impacted specimens. It can be observed from the same figure that the absorbed energy decreased significantly with increasing incident energy level. The 29 Joules post impacted samples have the lowest absorbed energy compared to all other categories of the samples. This is attributed to lower impact resistance of the samples caused by matrix cracking and fibre breakage at higher incident energy level.

The average results obtained from the post impacted specimens (Table 2) show a significant decrease in peak load and energy bearing capabilities for the flax/UP composites compared to just impacted samples. The peak load and energy absorption for the 25 Joules energy flax/UP sample without post impact were $5324 \mathrm{~N}$ and 26 Joules, whereas at similar energy level, for post impacted sample, the results were $3375 \mathrm{~N}$ and 23 Joules, which was decreased approximately by $37 \%$ and $12 \%$, respectively. As can be seen from the Table 2 , at higher energy, i.e. 29 Joules, both peak load and energy absorbed have been reduced significantly as a result of post impact damage effect. The peak load and energy absorption for the $29 \mathrm{~J}$ just impacted samples were $5221 \mathrm{~N}$ and $31 \mathrm{~J}$, respectively, whereas at similar energy level, for the post impacted samples, the results were $2530 \mathrm{~N}$ and $17 \mathrm{~J}$, which was decreased of approximately $52 \%$ and $45 \%$, respectively. The significant reduction of both peak load and energy absorption of the $29 \mathrm{~J}$ post impacted sample is related to the delamination and fibre fracture, considered as classical mode of failure in composites [27, $28]$.

\subsection{Finite element analysis (FEA)}


In Figures 5 and 6, force-time and kinetic energy-time curves of impact and postimpact response of composite plates which were extracted from FEA model are presented. The main reason for difference between FEA and experimental results might come from deletion of elements after failure of all composite layers during the impact simulation. In this case, there is no more resistance against the striker, therefore, few discrepancies are observed between experimental and FEA results. However, the experimental and FEA results of the composite plate have fairly good agreement. Different stages of impact and post-impact process for composite plate are shown in Figures 7- 9. It is evident that the composite plate absorbed the impact energy with fracture in the middle of composite plate. In comparison with numerical modelling in previous research, new Finite Element (FE) technique was developed in this paper which modeled the damaged area within composite structures using integration points to control stiffness of elements on the damaged area. Therefore, the proposed model in this paper can be also used for designing and estimating the mechanical performances of damaged composites joints and evaluating the stress trends on the damaged area. This model can be also used for designing and/or estimating the mechanical performances of damaged composites joints and evaluating the stress trends on the damaged area.

\subsection{Impact damage evaluation}

Typical damage patterns of specimens after post impact loading is shown in Figures 10-12. Figure 10 shows damage incurred by samples post impacted at 25 Joules. The depth of impact tup penetration was approximately $21 \mathrm{~mm}$ where the tearing of composite, fibre breakage and circumferential fracture lines were also visible. Figure 11 shows damage incurred for 27 Joules post impacted samples. A similar trend can be observed as it was for 25 Joules sample apart from higher impact tup penetration which was recorded approximately $21.5 \mathrm{~mm}$. In Figure 12, The 29 Joules post impacted samples show penetrated samples with 
biggest impact tup penetration depth $(24 \mathrm{~mm})$ as an evidence of much larger damage areas. The rear faces of all samples show pyramid protruded fracture as well as tear damaged areas. A similar trend has been reported by Ude et al. [29] where they have investigated the degree of damage inflicted on the reinforced composite face-sheet and sandwich foam, core materials used in sandwich panels. The extent of damage varies for flax/UP post impacted specimens depending on incident energy level applied (Table 2). The impacted front and the rear faces of the specimens show that as the incident energy increased, the damage area also increased.

It is noticeable from the post impacted damage images (Figures 10-12) that the extent of damage at the rear faces of all samples is greater than that of front faces as evidenced by matrix cracking and fibres fractures as a result of projectile fully penetrating the composite laminates. Damage incurred on these composites appears to be more local around the impacted site.

Impact response and failure modes of composite specimens were further characterised using SEM. As discussed, the energy used was up to the penetration, the damage mechanisms involved comprise of matrix cracking (Figure 13a), matrix cracking and delamination (Figure 13b) and fibre breakage and fibre pull out (Figure 13c). In this experiemntal study, the composites were impacted up to penetration and as a result, the damage was clearly visible. But in low velocity impact testing, where the specimens were not fully penetrated and specimen failed and delamination occured. Consequently, the situation can be very dangerous, because they are not easily detected visually and can lead to severe structural failure [30].

\section{CONCLISIONS}


In this study, the effect of post impact damage on the structural integritiy and the damage modes of flax/UP composites were investigated. A comparison between the experimental data and the numerical modelling has been made to analyse the post impact performance. It is evident to conclude that post impact damage caused a significant load reduction. The peak load and energy absorption for the 29 Joules impacted samples were $5221 \mathrm{~N}$ and 26 Joules, respectively. Whereas, at the similar energy level, for the post impacted samples, the results were $2530 \mathrm{~N}$ and 17 Joules, which was decreased by approximately $52 \%$ and $21 \%$, respectively.

The results showed that post impact resistance behavior of flax composites were significantly influenced by the employed incident energy value. For all samples, the damage area increased as the incident energy level increased. The numerical studies in LSDYNA was successfully validated experimental data and good agreement was found between experimental and numerical results. This numerical model is capable to predict the impact and post impact behavior of composite panels with variable thickness and layups.

\section{References}

[1] Faruk, O, Bledzki AK, Fink, HP, Sain, M. Biocomposites reinforced with natural fibres:2000-2010. Progress in Polymer Science 2012, 37:1552-1596.

[2] Bolton J. The Potential of Plant Fibres as Crops for Industrial Use. Outlook on Agriculture 1995; $24: 85-9$.

[3] Bledzki AK, Gassan J. Composites reinforced with cellulose base fibres. Prog Polym Sci 1999, 24: 221-74.

[4] Adekunle K, Akesson D, Skrifvars M. Mechanical and viscoelastic properties of soybean oil thermoset reinforced with jute fabrics and carded lyocell fiber. Journal of Applied Polymer Science 2011; 122(5): 2855-2863. 
[5] Dhakal HN, Zhang ZY, Richardson MOW. Effect of water absorption on the mechanical properties of hemp fibre reinforced unsaturated polyester composites. Compos Sci Technol. $2007 ; 67: 1674-1683$.

[6] Dhakal, H.N., Zhang, Z. Y. and Richardson, M. O. W. Creep behaviour of hemp fibre reinforced unsaturated polyester composites. Journal of Biobased Materials and Bioenergy $2009 ; 3: 232-237$.

[7] Sombatsompop N, Chaochanchaikul K. Effect of moisture content on mechanical properties, thermal and structural stability and extrudate texture of poly(vinyl chloride)/wood sawdust composites. Polym Int. 2004; 53: 1210-18.

[8] Jacob M, Thomas S, Varughese KT. Mechanical properties of sisal/oil palm hybrid fibre reinforced natural rubber composites. Compos Sci Technol 2004; 64: 955-65.

[9] Bledzki AK, Gassan J, Zhang W. Impact properties of natural fibre reinforced epoxy foams. J Cell Plast 1999; 35: 550-62.

[10] Gassan J, Cutowski VS. Effect of corona discharge and UV treatment on the properties of jute-fiber epoxy composites. Compos Sci Technol 2000; 60: 2857-63.

[11] Dhakal HN, Zhang ZY, Guthrie R, Bennett N. Development of flax/carbon fibre hybrid composites for enhanced properties. Journal of Carbohydrate Polymers, 2013 96:1-8.

[12] Dhakal HN, Zhang ZY, Richardson MOW, Errajhi OAZ. The low velocity impact response of non-woven hemp fibre reinforced unsaturated polyester composites. Compos Struct. 2007; 81: 559-67.

[13] De Rosa, Igor M. Dhakal HN. Santulli C, Sarasini F. Zhang ZY. Post-Impact Static and Cyclic Flexural Characterisation of Hemp Fibre Reinforced Laminates. Composites Part B 2012; 43:1382-1396.

[14] Dhakal HN, Zhang ZY. Bennett N. Reis PNB. Low-velocity impact response of nonwoven hemp fibre reinforced unsaturated polyester composites: Influence of impactor geometry and impact velocity. Composite Structures, 2012; 94: 2756-2763

[15] Cantwell WJ, Morton J. The impact resistance of composite materials; a review. Composites 1991; 22: 347-62. 
[16] Choi HY, Wu HYT, Chang FK. A new approachtoward understanding demage mechanisms and mechanics of laminated composites due to low-velocity impact: Part IIanalysis. J. Compos. Mater., 1991, 25, 101201038.

[17] Wisheart M, Richardson MOW. Low velocity response of a complex geometry pultruded Glass/Polyester Composite. J Mater Sci 1999; 34: 1107-16.

[18] Mitrevski T, Marshall IH, Thomson R. The influence of impactor shape on the damage to composites laminates. Compos Struct 2006; 76: 116-22.

[19] Bledzki AK, Mamum AA, Faruk, O. Abca fibre reinforced PP composites and comparison with jute and flax fibre PP composites. eXpress Polymer Letter 2007; 1:755-762.

[20] Benevolenski OI, Karger-Kocsis J, Mieck KP, Reubmann T. Instrumented performation impact response of polypropylene composites with hybrid reinfrocement flax/glass and flax/cellulose fibres, Journal of Thermoplastic Composite Materials 2000; 13:

[21] Santulli C. Falling weight impact damage characterisation on flax/epoxy laminates. International Journal of Materials and Product Technology; 36:221-228.

[22] Santulli C. and Caruso AP. A comparative study on falling weight impact properties of jute/epoxy and hemp/epoxy laminates. Malaysian Polymer Journal, 2009; 4:19-29.

[23] Ghasemnejad H, Soroush V.R, Mason P.J, Weager B, To improve impact damage response of single and multi-delaminated FRP composites using natural Flax yarn. Materials and Design, 2012;36, 865-873.

[24] Ghasemnejad H, Furquan A.S.M, Mason P.J. Charpy Impact Behaviour of Single and Multi-Delaminated Hybrid Composite Beam Structures. Materials and Design, 2010;31: 3653-3660.

[25] Chang FK, Chang, KY. A progressive damage model for laminated composites containing stress concentrations. Journal of Composite Materails 1987;21:834-855.

[26] Hashin Z. Failure criteria for unidirectional fibre composites. Journal of Applied Mechanics 1980; 47:329-334.

[27] Jawaid M, Abdul Khalil HPS. Cellulisic/synthetic fibre reinforced polymer hybrid composites: A review. Carbohydrate Polymers 2011; 86:1-18. 
[28] Tan KT, Watanabe N. Impact damage resistance, response and mechanisms of laminated composites reinforced by through-thickness stitching 2012; 21:51-80.

[29] Ude AU, Ariffin AK, Azhari CH. Impact damage characteirstics in reinforced woven natural silk/epoxy composite face-sheet and sandwich foam, coremat and honeycomb materials. International Journal of Impact Engineering 2013; 58:31-38.

[30] Arumugam V, Suresh Kumar C, Santulli C, Sarasini F, Joseph Stanley A. A Global Method for the Identification of Failure Modes in Fiberglass Using Acoustic Emission. Journal of Testing and Evaluation 2011; 39:103730.

Table 1: Physical and mechanical properties of flax fibre bundle $[5,25]$

\begin{tabular}{ccccccc}
\hline Material & $\begin{array}{c}\text { Length of } \\
\text { fibre }(\mathrm{mm})\end{array}$ & $\begin{array}{c}\text { Diameter of } \\
\text { fibre }(\mu \mathrm{m})\end{array}$ & $\begin{array}{c}\text { Density } \\
\left(\mathrm{g} / \mathrm{cm}^{3}\right)\end{array}$ & $\begin{array}{c}\text { Young's } \\
\text { modulus } \\
(\mathrm{GPa})\end{array}$ & $\begin{array}{c}\text { Tensile } \\
\text { strength } \\
(\mathrm{MPa})\end{array}$ & $\begin{array}{c}\text { Elongation } \\
\text { at break } \\
(\%)\end{array}$ \\
\hline Flax & $10-65$ & $5-38$ & 1.4 & $60-80$ & $500-900$ & $1.2-1.6$ \\
& & & & & & $2000-3500$ \\
\hline E-glass * & 7 & 13 & 2.5 & 70 & &
\end{tabular}

*For comparison purpose

Table 2: Summary of impact test results for different samples

\begin{tabular}{ccccccc}
\hline Sample type & $\begin{array}{c}\text { Rear face } \\
\text { damage area } \\
\left(\mathrm{mm}^{2}\right)\end{array}$ & $\begin{array}{c}\text { Peak load } \\
(\mathrm{N})\end{array}$ & $\begin{array}{c}\text { Peak load } \\
\text { impacted }\end{array}$ & $\begin{array}{c}\text { Energy }(\mathrm{J}) \\
\text { impacted } \\
\text { impacted }\end{array}$ & $\begin{array}{c}\text { Energy }(\mathrm{J}) \\
\text { post } \\
\text { impacted }\end{array}$ & $\begin{array}{c}\text { Rear damage } \\
\text { height }(\mathrm{mm})\end{array}$ \\
\hline $25 \mathrm{~J}$ & 930 & 5324 & $3375(-37 \%)$ & 26.0 & $23(-12 \%)$ & 21.0 \\
\hline $27 \mathrm{~J}$ & 1102 & 5140 & $3022(-41 \%)$ & 28.0 & $22(-21 \%)$ & 21.5 \\
\hline $29 \mathrm{~J}$ & 1110 & 5221 & $2530(-52 \%)$ & 31.0 & $17(-45 \%)$ & 24.0
\end{tabular}

\section{Figure captions}

Figure 1: Zwick/Roell HIT230F drop weight impact tower 
Figure 2. Finite element (FE) model of striker and plate in LSDYNA, a) front view and b) plane view

Figure 3: Comparison of load vs. time curves (a) just impacted samples (b) post impacted samples

Figure 4: Comparison of energy vs. time curves (a) just impacted samples (b) post impacted samples

Figure 5: Representative force-time curves for impact and post impact response of $29 \mathrm{~J}$ specimens

Figure 6: Kinetic energy dissipation vs time under impact energy of $29 \mathrm{~J}$

Figure 7: Illustration of element deformation showing hemispherical impact (29J) on specimen surface a) plane view and b) side views

Figure 8: Illustration of element deformation showing hemispherical post-impact (29J) on impacted specimen surface a) plane view and b) side views

Figure 9: Comparison between impacted plate in Experiment and FEM.

Figure 10: Pictures of post impacted damage at $25 \mathrm{~J}$ (a) rear faces (b) front faces

Figure 11: Pictures of post impacted damage at $27 \mathrm{~J}$ (a) rear faces (b) front faces

Figure 12: Pictures of post impacted damage at $29 \mathrm{~J}$ (a) rear faces (b) front faces

Figure 13: SEM images showing failure modes (a) matrix cracking, (b) delamination and (c) fibre breakage 


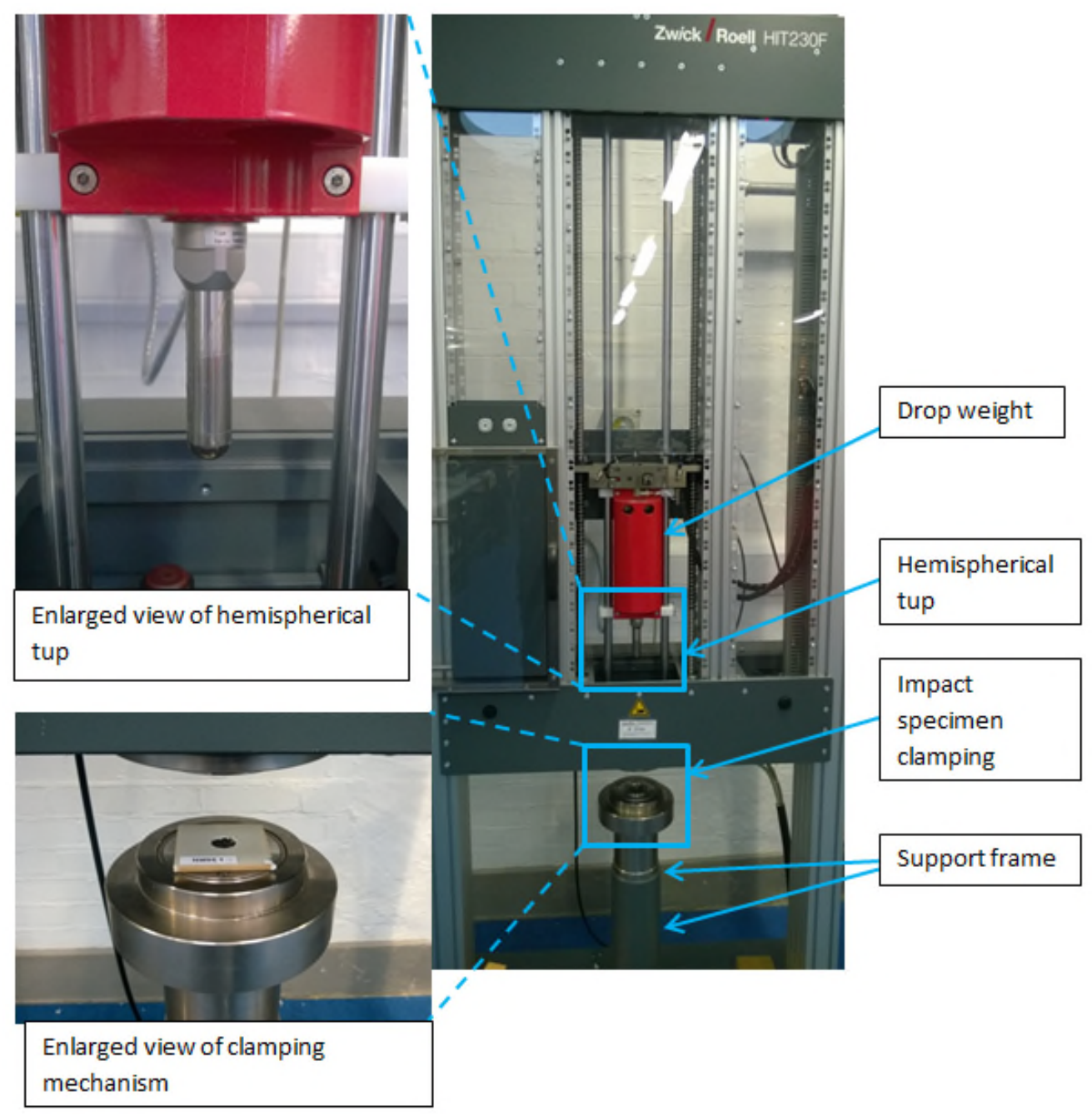

Figure 1: Zwick/Roell HIT230F drop weight impact tower 


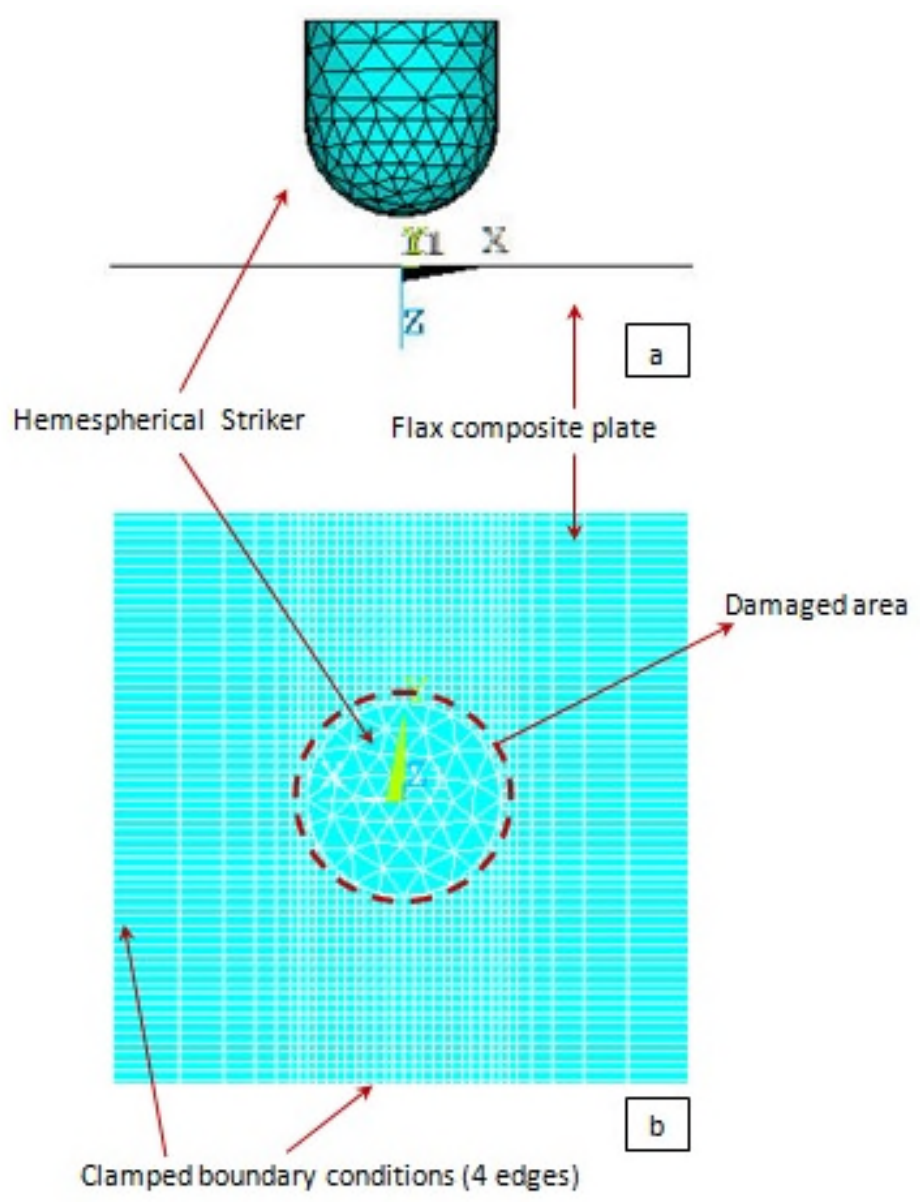

Figure 2. Finite element (FE) model of striker and plate in LSDYNA, a) front view and b) plane view 

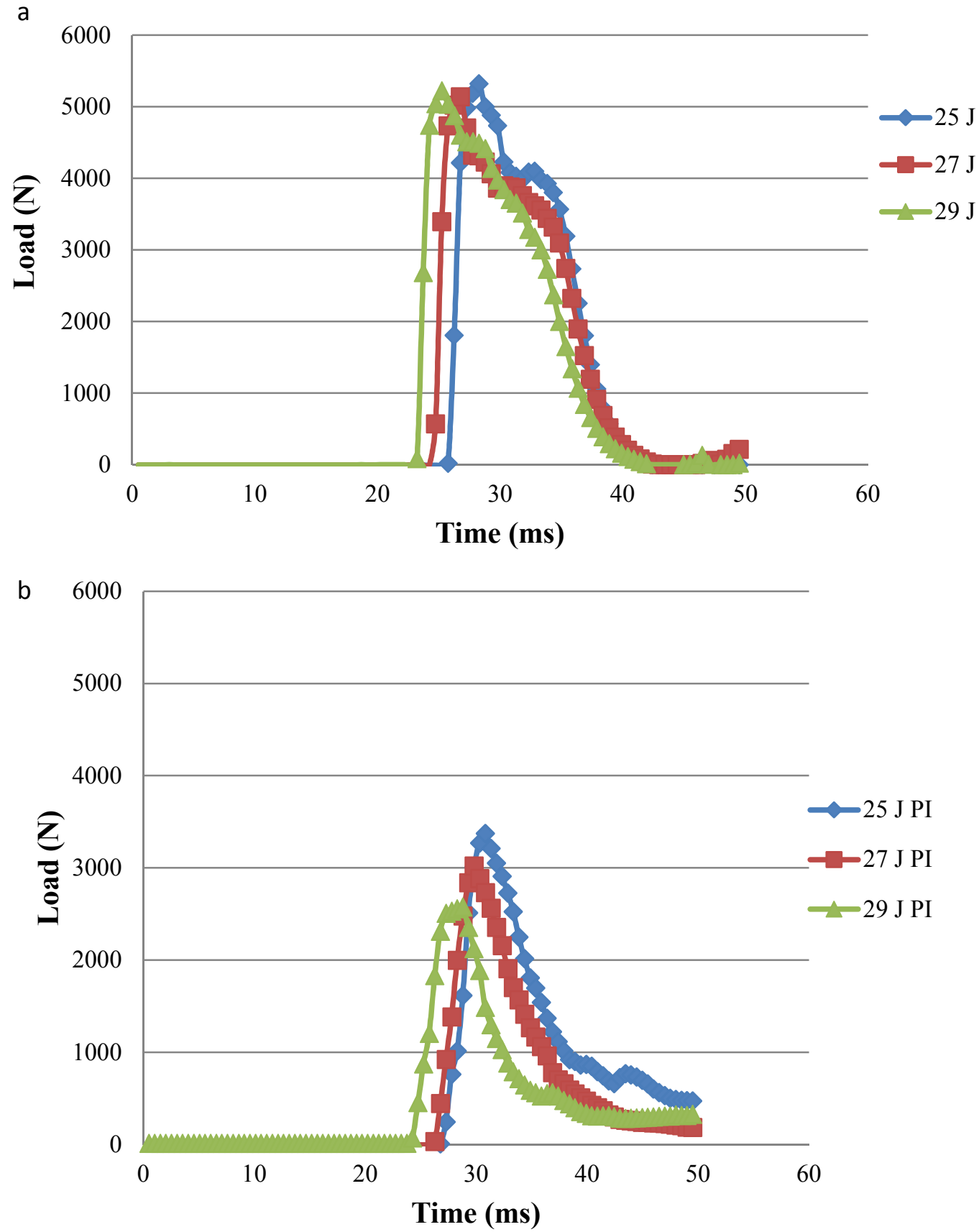

Figure 3: Comparison of load vs. time curves (a) just impacted samples (b) post impacted samples 

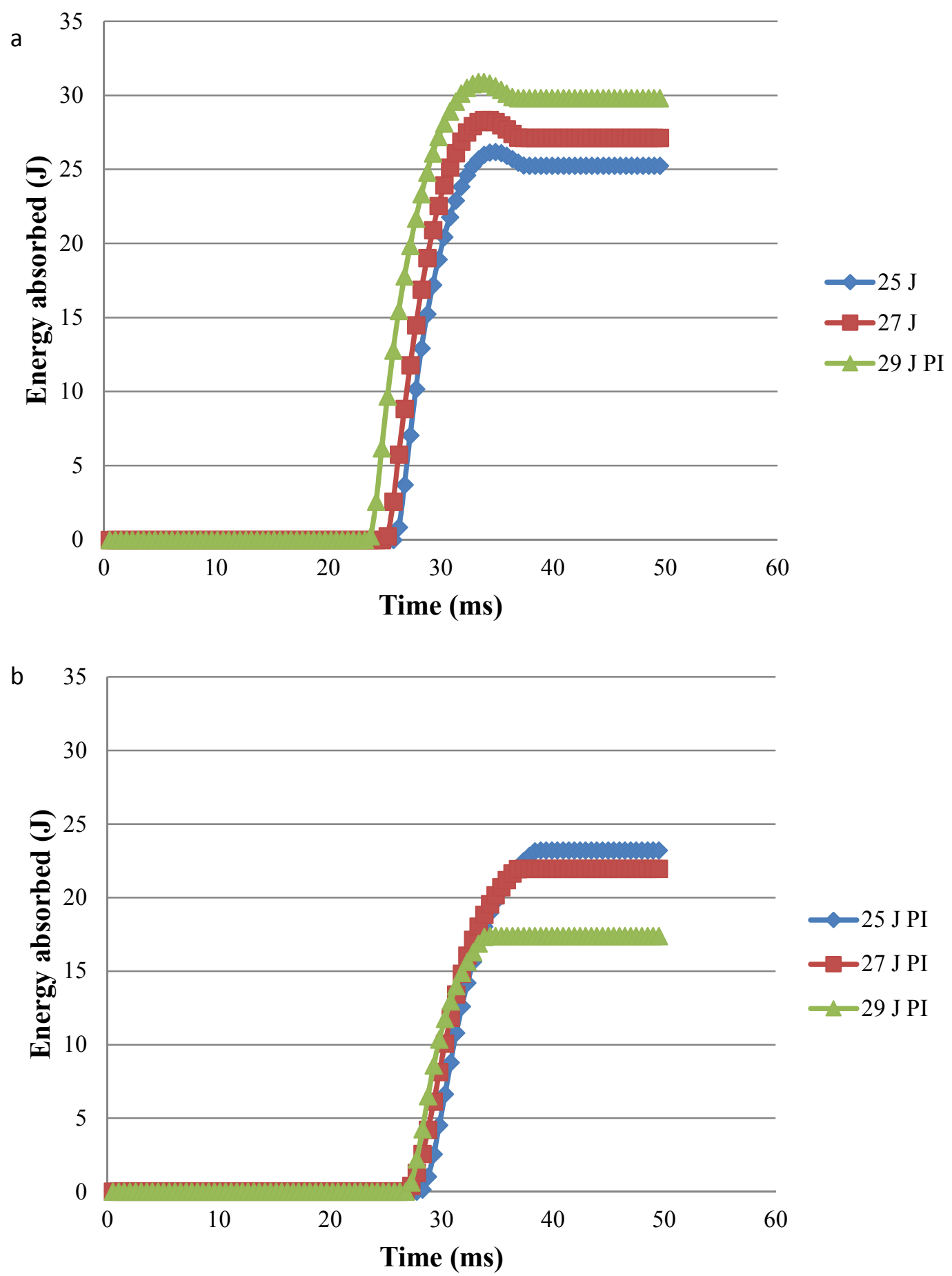

Figure 4: Comparison of energy vs. time curves (a) just impacted samples (b) post impacted samples 


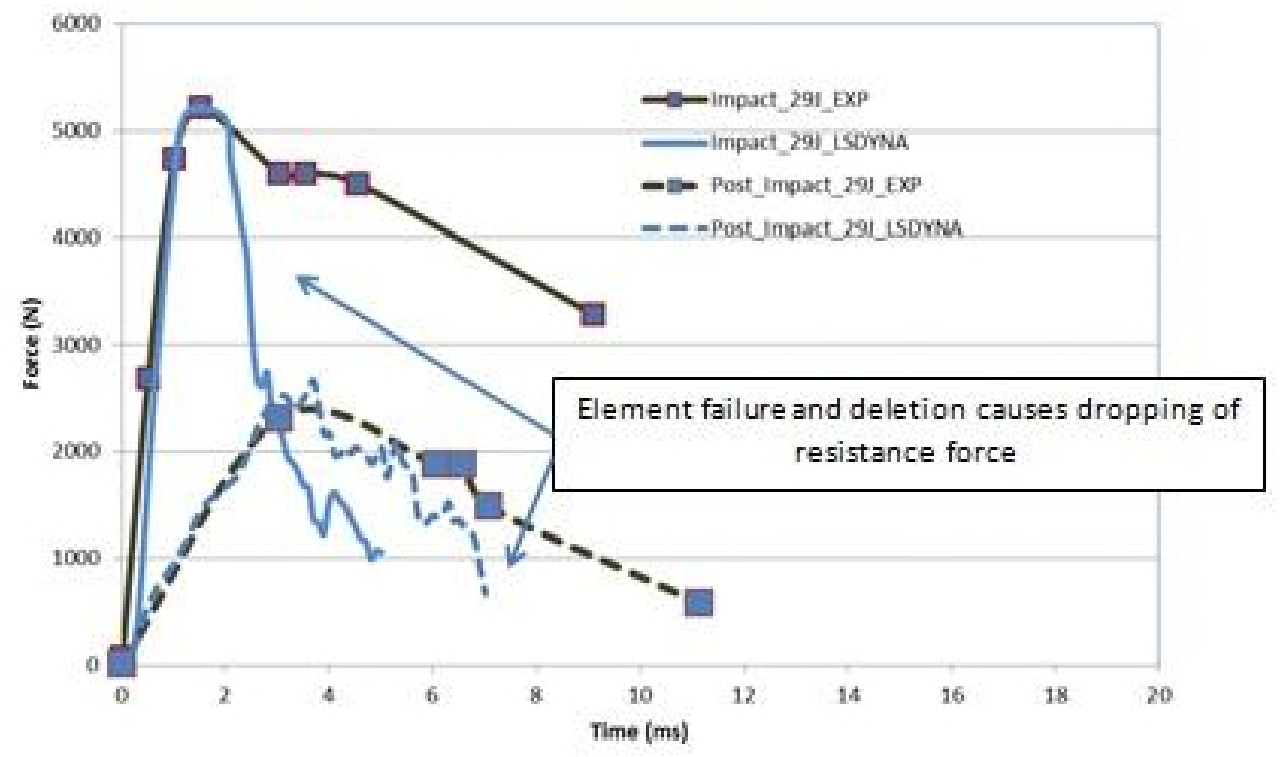

Figure 5: Representative force vs. time curves for impact and post impact response of $29 \mathrm{~J}$ specimens

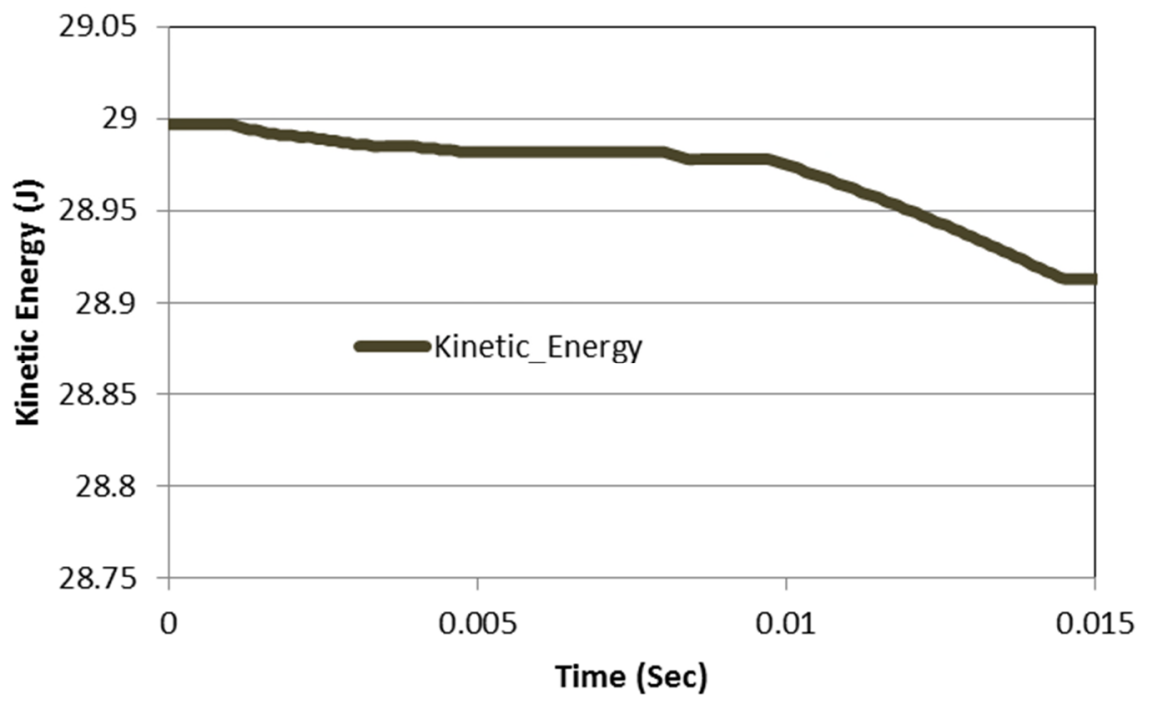

Figure 6: Kinetic energy dissipation vs time under impact energy of 29J 

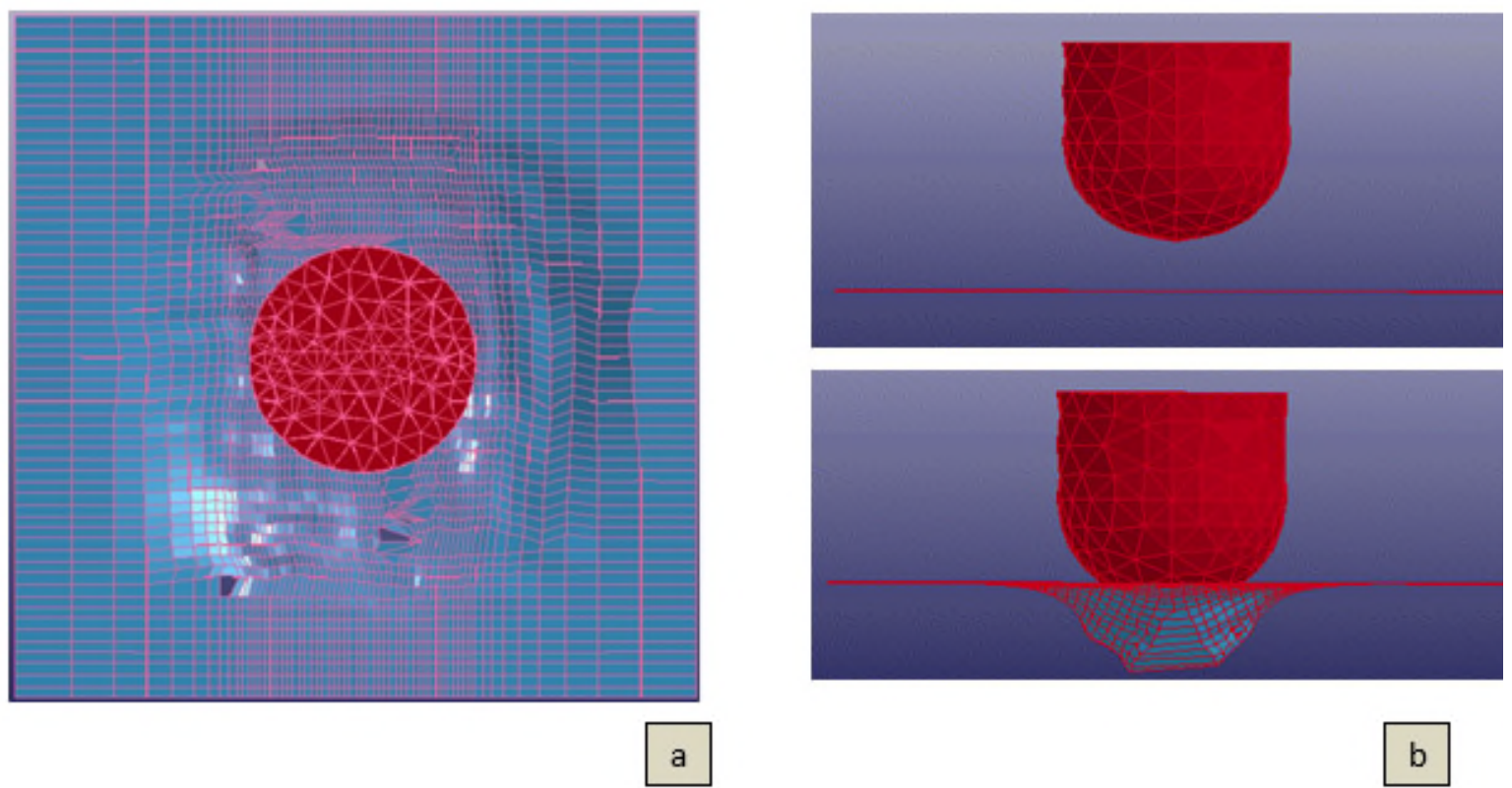

Figure 7: Illustration of element deformation showing hemispherical impact (29J) on specimen surface a) plane view and b) side views before and after impact.

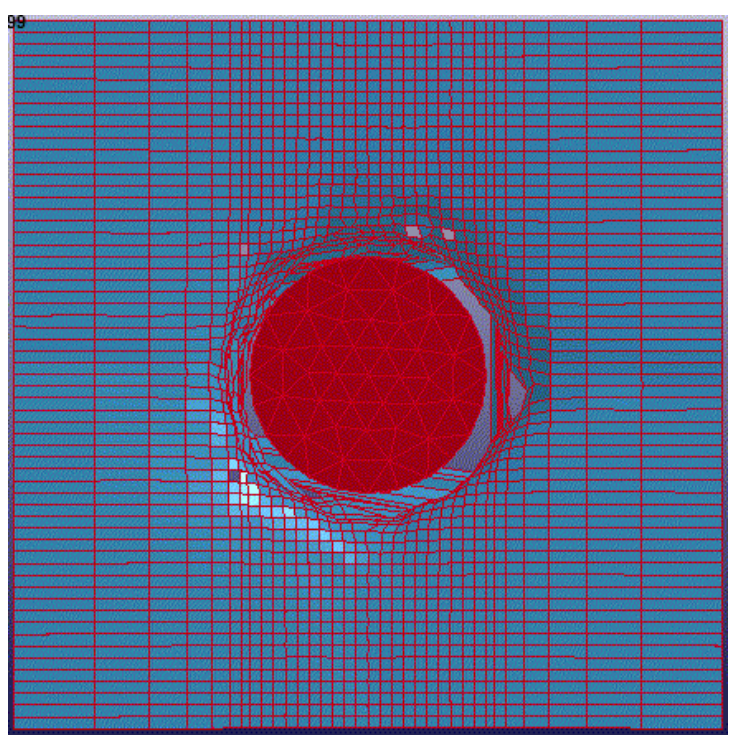

a
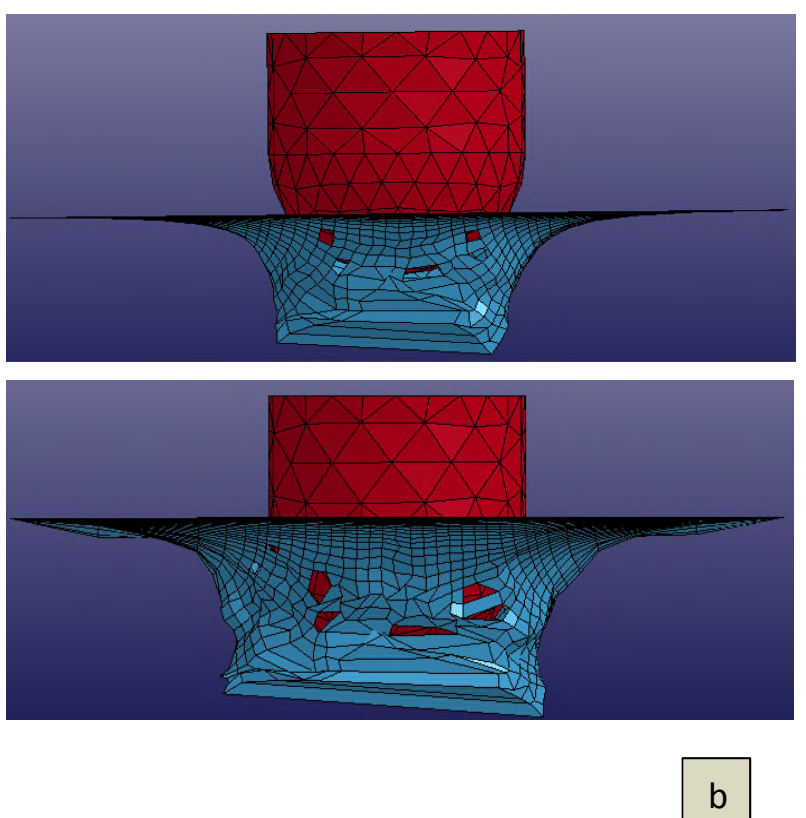

Figure 8: Illustration of element deformation showing hemispherical post-impact (29J) on impacted specimen surface a) plane view and b) side views 

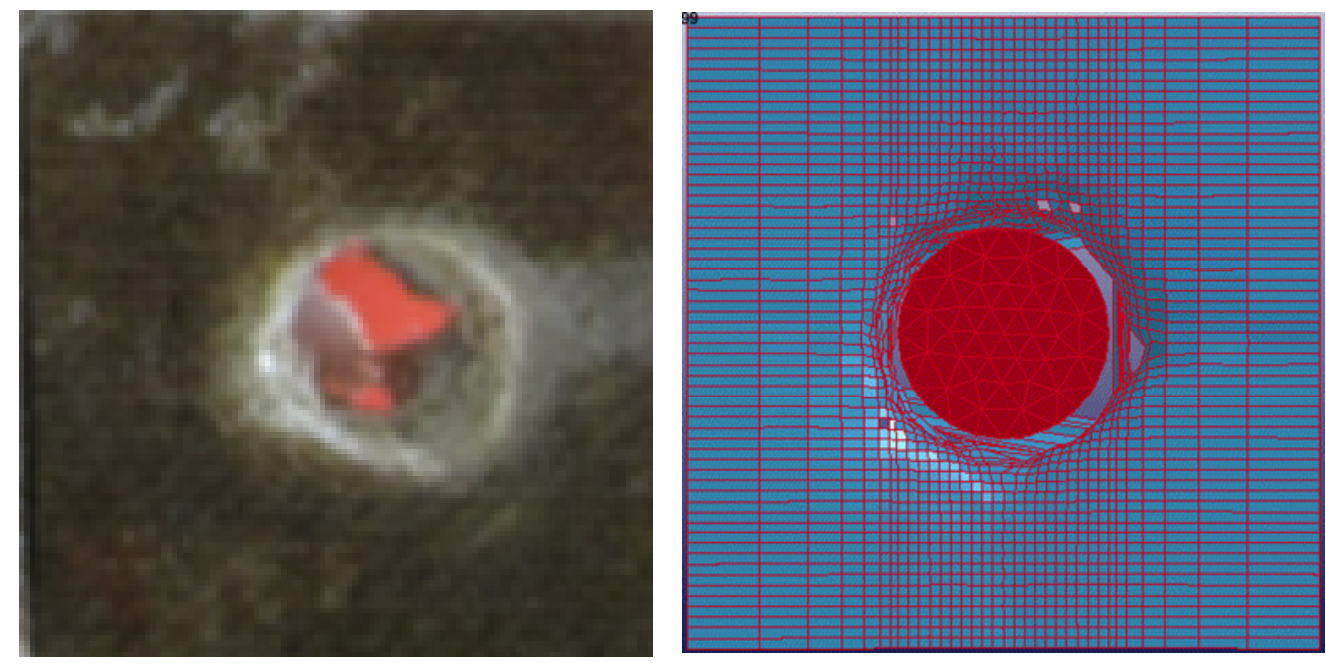

Figure 9: Comparison between impacted plate in Experiment and FEM.

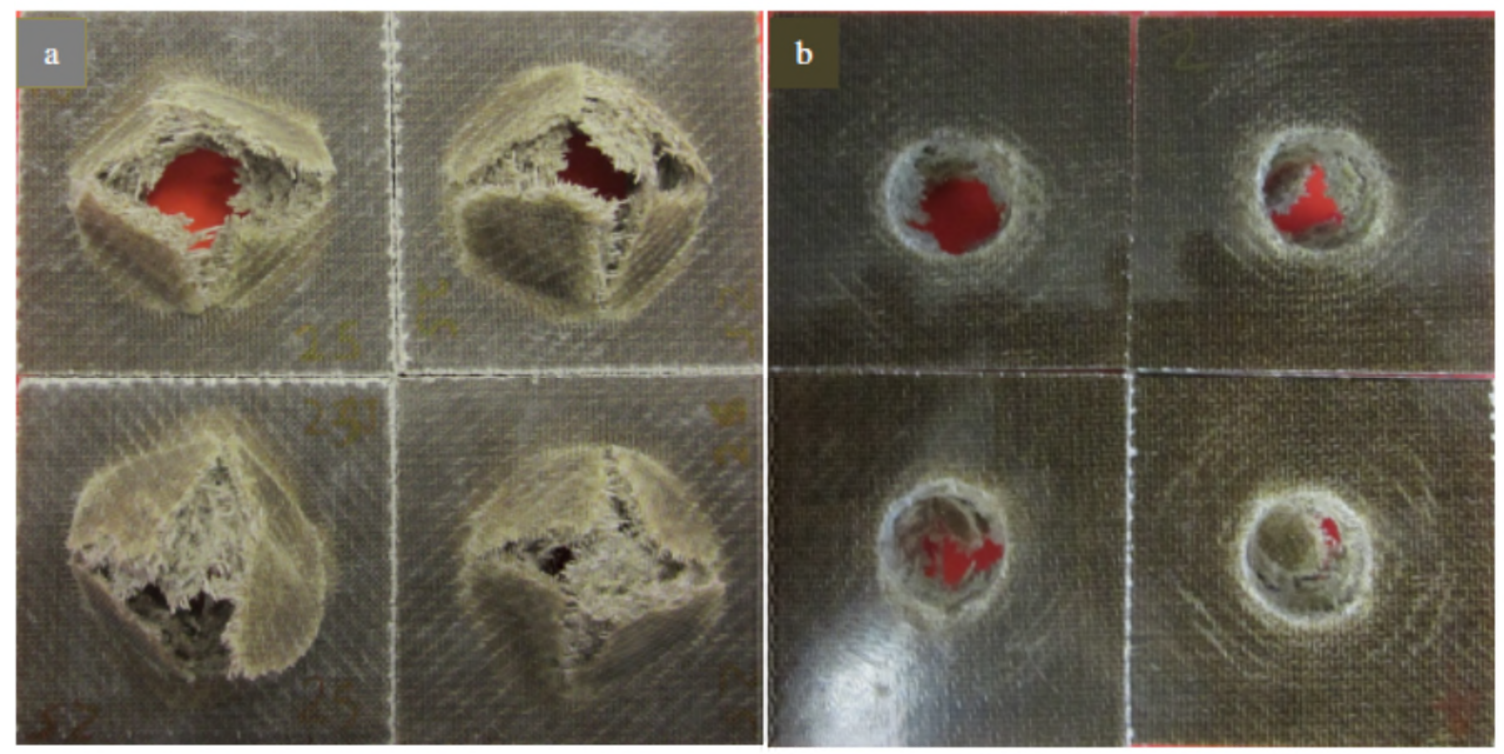

Figure 10: Pictures of post impacted damage at $25 \mathrm{~J}$ (a) rear faces (b) front faces 


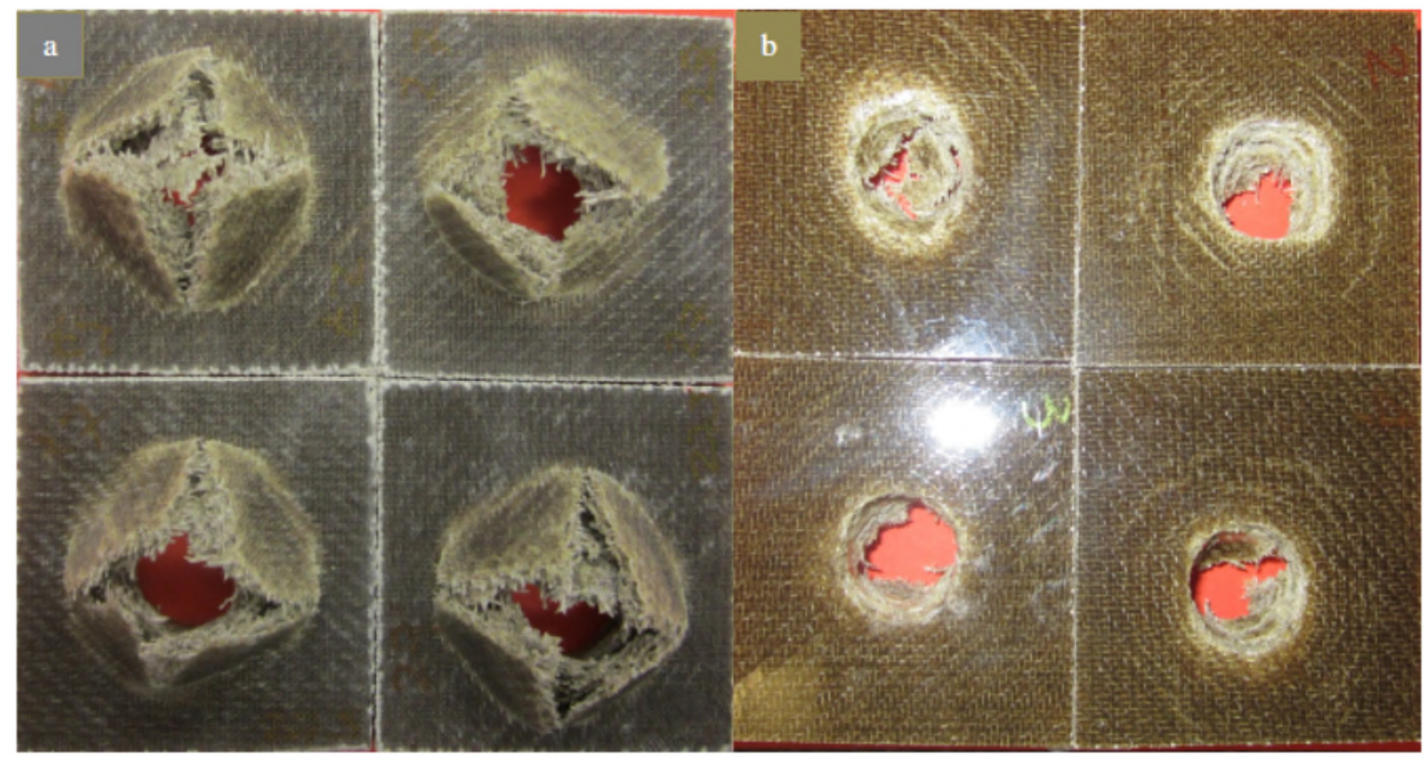

Figure 11: Pictures of post impacted damage at $27 \mathrm{~J}$ (a) rear faces (b) front faces

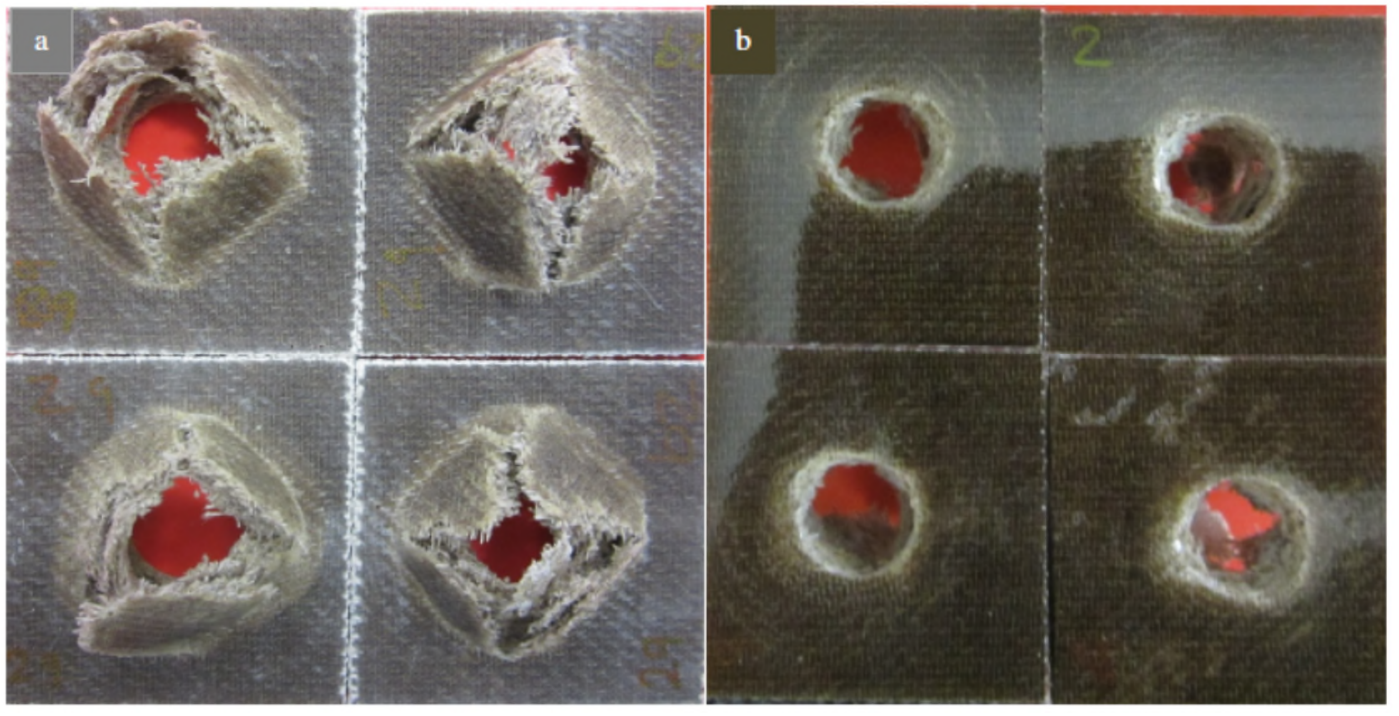

Figure 12: Pictures of post impacted damage at $29 \mathrm{~J}$ (a) rear faces (b) front faces 

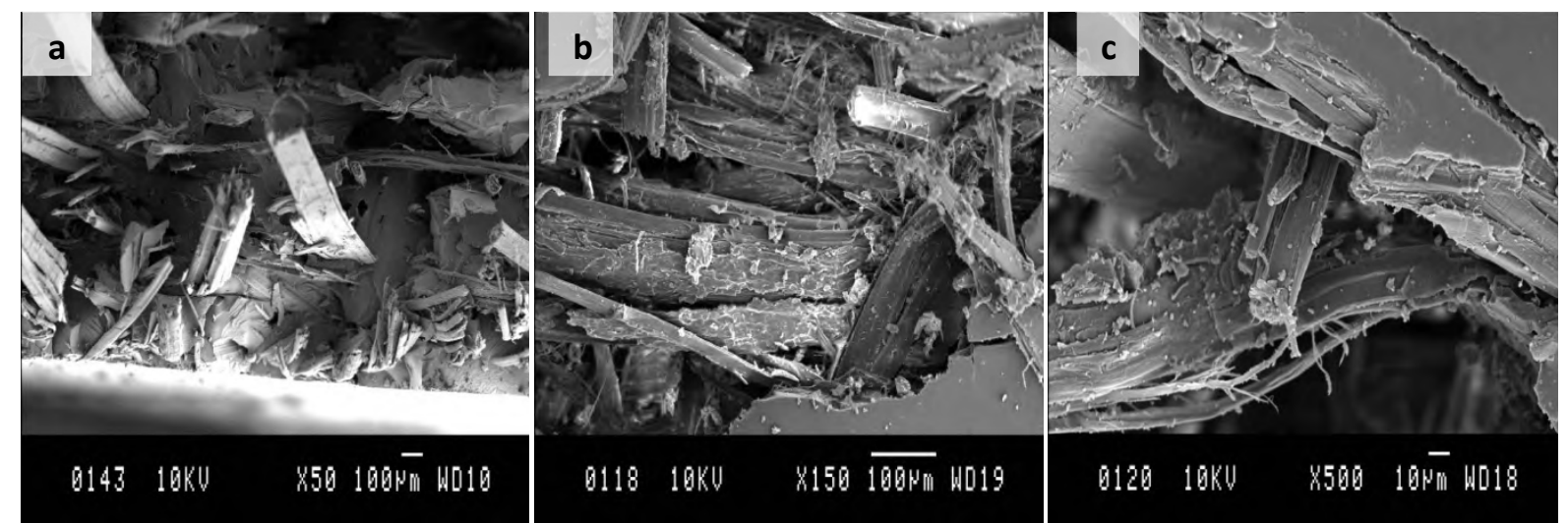

Figure 13: SEM images showing failure modes (a) matrix cracking at lower magnification, (b) matrix cracking and delamination and (c) matrix cracking, delamination and fibre breakage 
2018-01-08

The post-impact response of flax/UP composite laminates under low velocity impact loading

\author{
Dhakal, H. N.
}

SAGE

Dhakal HN, Ghasemnejad H, Zhang ZY, et al. The post-impact response of flax/UP composite laminates under low velocity impact loading. International Journal of Damage Mechanics, available online 8 Januaary 2018 https://doi.org/10.1177/1056789517751239

Downloaded from Cranfield Library Services E-Repository 